\title{
Reframing Vacancy: Designing and Rebuilding in Post-Recession Cleveland
}

\author{
KRISTEN ZEIBER \\ Kent State University
}

From 2014 through 2016, an architecture school in Northeast Ohio worked to rehabilitate a vacant house in Cleveland. The project was speculative: there was no client, only a hypothetical end buyer. The building chosen, a sturdy brick 1920s house, was abandoned, condemned, and had narrowly avoided demolition. The neighborhood, St. Clair-Superior, had a median household income of $\$ 19,000$; a median home sale price of under $\$ 10,000$; and dozens of other vacant houses within a block. Nevertheless, the design team believed in the potential for architecture students, stepping in where the private sector would not, to pool their creative energies and labor to create a project that could simultaneously teach the students about the real-world complications to their studio ideas and also deliver an attractive, market-friendly home back into the larger urban fabric of a distressed neighborhood.

The project was ambitious and the stakes were high, particularly for a new design/build program. Though the house was eventually sold, throughout the process the project wrestled with the same questions many design/build projects do: What constitutes the best "design decision" when working with real materials and a real user? Who makes those decisions - students, instructors, neighborhood partners, someone else? How can we as educators ensure that the pedagogical needs of the architecture students are being met, while ultimately in service of a larger end product? Uniquely, however, this project also attempted to answer the question: can a lowcost residential design/build program point a way forward for tackling Cleveland's vacant housing and stemming the loss of the city's historic neighborhoods?

Over the course of the project, the mission - to reclaim one of Cleveland's many vacant houses - struggled to perfectly align with the simultaneous pedagogy of learning by doing, causing tensions and setbacks. That tension, however, was ultimately an opportunity for growth and learning for the students, instructor, and project manager alike.

\section{CONTEXT: SHRINKING CITY, VANISHING NEIGHBORHOODS}

Like many legacy cities in the Great Lakes region, Cleveland has been steadily losing population since 1950. At one point nearing a million inhabitants, the city population has decreased to approximately 388,000 residents. The foreclosure crisis of the mid-2000s hit Cleveland's neighborhoods especially hard; in some parts of the city, 1 in every 3 homes faced foreclosure. Many of these homes, subsequently abandoned, were stripped by scrappers or simply left to decay.

At these current rates, approximately 18 houses in Northeast Ohio will be abandoned every day from now until 2040, largely
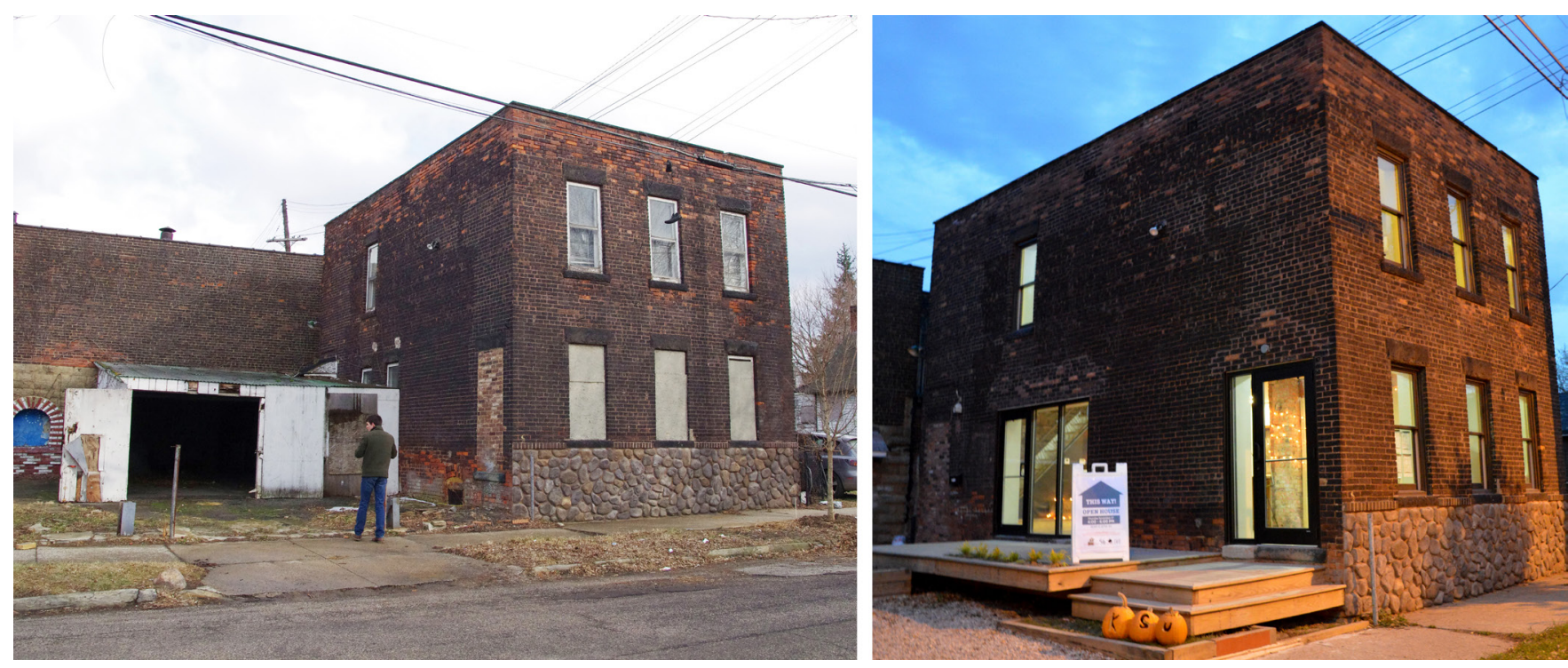

Figure 1: The vacant house before, and the final result: a single-family brick loft home with a side deck, subsequently sold to a new owner 
due to population loss, weak market demand, and sprawling land use $^{1}$. By some estimates, Cuyahoga County currently has over 20,000 vacant houses; approximately 1,000 of these are demolished every year, generating an enormous volume of debris for local landfills ${ }^{2}$. The vacant lots remaining are generally left undeveloped for years, systematically erasing the city's historic urban fabric.

Many of these homes are beyond saving, but some are merely overlooked and undervalued. If renovated in a cost-effective way, they might be able to fill an affordable housing gap, while simultaneously preserving the historic city and preventing further landfilling. Reclaiming some of Cleveland's existing housing seemed a far more urgent framing for a new design/build program than generating any new structure. The hypothesis of this third-year undergraduate design/build studio was that architecture students, working quickly and collaboratively in both the studio and on site, could generate affordable, creative design ideas to step in where a lack of market demand and investment threaten our historic cities. In the process, the program could make an argument for reclaiming the city's historic houses as a way to not only preserve our historic neighborhood fabric, but also create affordable housing options within the city for those not able to build entirely new construction.

In the fall before the spring design studio began, the studio instructor, teaching at the University, and the project manager, located in the University's Community Design Center in Cleveland, worked with local Community Development Corporations (CDCs) and the local Land Bank in order to identify potential vacant houses and inspect them. Three neighborhoods were identified as likely candidates for such a home - each of these three neighborhoods were at somewhat of a "tipping point," economically, where vacant houses were not being purchased and redeveloped by the private sector, but there had also not yet been a complete erasure of the existing urban fabric.

From there, the final decision lay mainly in finding the right house: the leadership team viewed many vacant houses in each neighborhood, inspecting each for not just existing conditions,

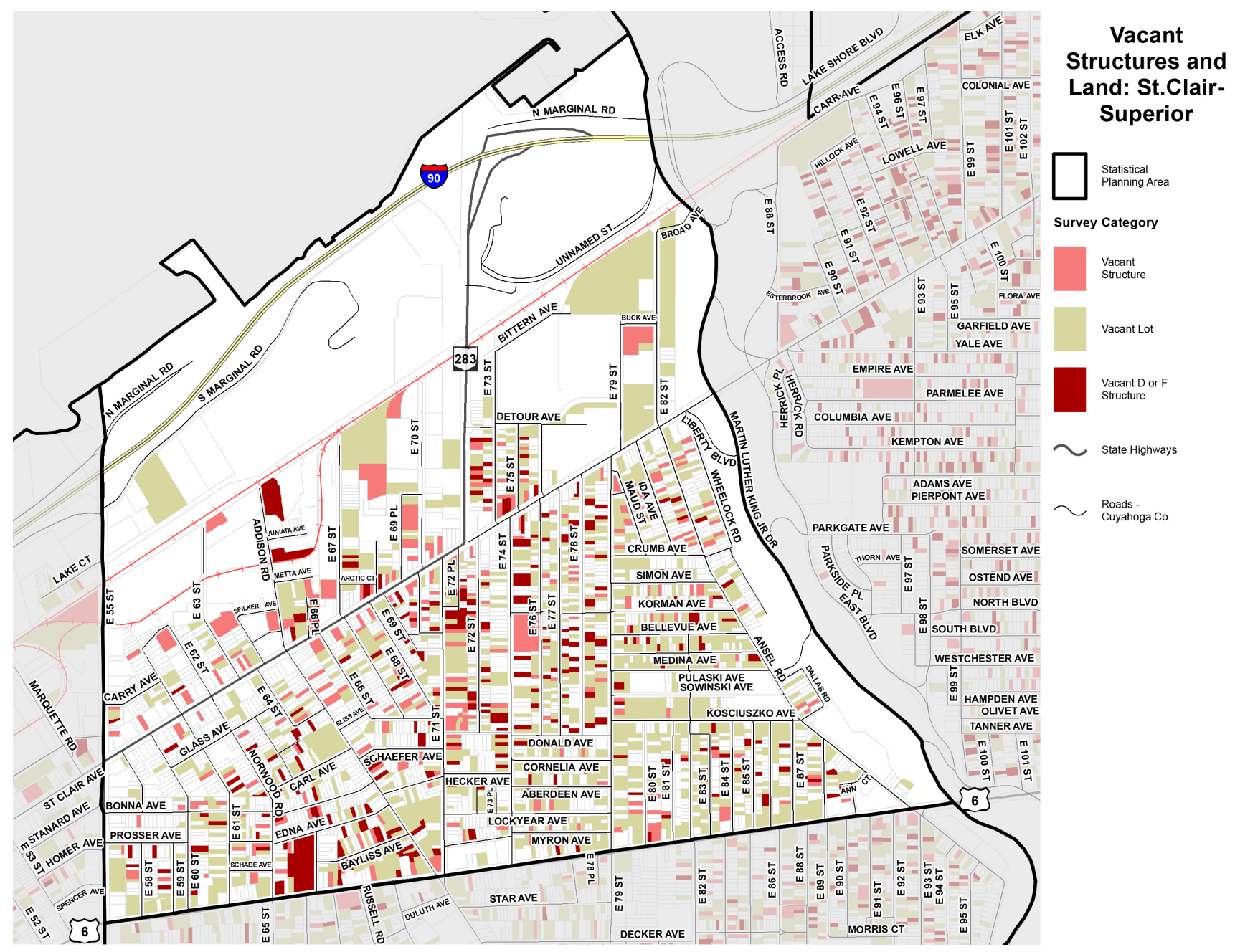

Figure 2: The neighborhood chosen, St Clair-Superior, was emblematic of many Cleveland neighborhoods, with a proliferation of distressed housing stock and vacant land. ${ }^{3}$ 
but also for design potential. Some homes, particularly the very old historic properties, did not seem to need the reinvention a full architecture studio could bring; often, they merely needed a straight renovation. Instead, the team focused their efforts on finding a house that could be creatively reimagined, perhaps with some special architectural or formal details not found elsewhere in the city.

The house the leadership team eventually identified as the ideal candidate was a small two-story brick cube with a flat roof, unusual in Cleveland. The existing property had a one-bedroom apartment on each floor, but the blank platonic form and the richly textured brick provided an ideal background for a variety of reconfiguration. More importantly, the house was owned by the local CDC, meaning the University would not have to take ownership - ideal in a situation with an uncertain end user, as the University did not want to become a landlord. The neighborhood was the most economically distressed of the three considered, but ultimately the team decided the house had enough architectural potential to justify the risk. Additionally, the neighborhood CDC was a past partner on other projects, and their staff was known to welcome experimental projects - one of their own initiatives was in providing housing for artists in the neighborhood, so their perspective on the vacant house influenced the students' own ideas about an end user towards a young creative professional.

\section{OPEN QUESTIONS, LESSONS LEARNED: WHAT PRECEDENTS?}

The University had no formalized design/build program when this project began; some faculty have used rapid prototyping and small-scale fabrication in their studios, but no ongoing program exposed architecture students to the realities of construction when a specific project and a specific client are in play. Instead, the design leadership team looked to other design/build programs as inspiration for structuring the project, namely the Rural Studio's 20K House program and bcWORKSHOP's Congo Street initiative in Dallas, TX.

The basic premise of Auburn University's Rural Studio 20K house program - creativity through budget limitations - was a strong touchpoint for the Cleveland project. Additionally, the program's focus on replicability for the private sector was an aspect the team admired and hoped to duplicate. However, the $20 \mathrm{~K}$ program is not directly translatable for a northern urban context - Cleveland's houses have stricter building codes and more robust thermal requirements. Many of the existing houses in the city are far larger than any of the modest shelters generated in Hale County, with accordingly greater material costs. Still, increasing the total construction budget to $\$ 30,000$ could theoretically keep the project within the realm of average home sale price and yet be restrictive for the Cleveland rebuild students, requiring some true innovation.
Meanwhile, bcWORKSHOP's Congo Street Initiative in Dallas was influential to the Cleveland program in its deep commitment to the people living on a single block in Dallas: the program systematically renovated and in some cases drastically altered the existing houses on the block, starting with a home that became known as the "holding" house. As the design/build team tackled a new home, that family would move into the holding house for the duration of the construction process, and then move back into their newly renovated home, vacating the holding house for the next neighbor. Similarly, the Cleveland program leaders did not want our project to be merely a drop in the bucket, especially in as distressed a neighborhood as St Clair-Superior; instead, the team felt committed to the idea that the ideas embodied in the house were replicable throughout the neighborhood and in other economically distressed areas of the city.

In reality, however, when the design team explored the neighboring vacant house, they found a home with a caved-in foundation, broken windows, stripped plumbing, and a leaking roof. Any one of these issues may have been surmountable, but all of them together rendered the neighboring house far beyond saving. The same held true for some of the others along the street. By the end of the first year of construction on the student house, 6 additional houses had been demolished in the immediate vicinity, leaving the student house surrounded by vacant lots. Though the Congo Street model was an appealing fantasy for the Cleveland context, in reality our initial hypothesis proved correct: some houses are worth saving, but unfortunately many more are not.

\section{WHAT BUDGET?}

With a house identified for the spring design studio, the Director of the Design Center acquired the initial grant money of $\$ 30,000$ from a local foundation. In close collaboration with the Design Center and the local CDC, the studio set out to redesign, gut, and renovate the house in order to sell it for at least that price and replicate the process with another vacant house in the neighborhood. The budget was incredibly lean on purpose - with such a low average resale value, there was no guarantee that the project would sell with any additional investment. Additionally, the tight budget provided equally tight design constraints on the students; any student's idea for how to renovate the house had to be as inexpensive as possible to implement, even without paying for labor.

In truth, the $\$ 30,000$ budget was a slight fiction for the house chosen--the house would need entirely new windows and mechanical, electrical, and plumbing systems, plus roof repairs and tuckpointing. A construction company local to the neighborhood volunteered to provide windows and roof \& masonry repairs pro bono, in order to lure the team to the neighborhood. Without this contribution, the project would not have been financially feasible. The team would most likely have chosen a house requiring less intensive reconstruction in an economically healthier neighborhood. 

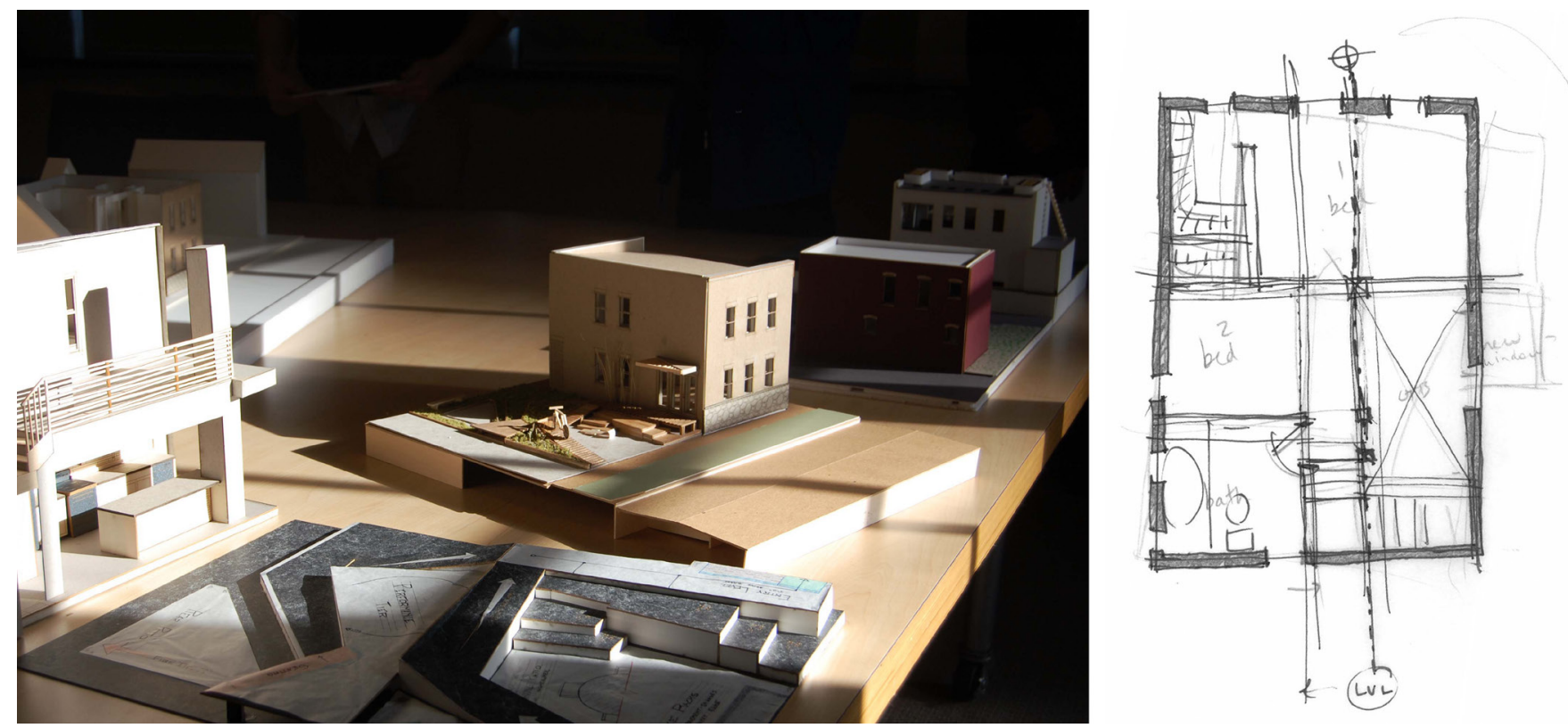

Figure 3: Student models and sketches were consolidated into one hybrid scheme

$\$ 30,000$ is still not very much for a full-gut renovation, even without removing a portion of the second floor to create a loft space. The budget was stretched to the limit, owing mainly to hiring a licensed contractor to install the MEP systems and unexpected costs like the rental costs for five Dumpsters the students filled with demolition debris. It quickly became clear that even with the donated windows and student labor, the $\$ 30,000$ number was simply far too low for a full-gut major renovation. An additional $\$ 10,000$ from another source supplemented the initial budget.

Since the original design studio, the University's construction management program has since been absorbed into the same College as the Architecture program, creating the potential for closer collaborations on projects like this. As it was, the studio instructor reached out to the Construction Management instructor teaching a course on cost estimation. In theory, the various design ideas the architecture students generated could be tested for their adherence to the budget, thereby informing which of those ideas were best suited for the project. In practice, however, the design students had barely enough time to send finished construction drawings over to the CM students and get rough cost estimates by the end of the semester. This timeline meant that one of the great potential strengths of the program - the active and ongoing collaboration between design ideas and their actual budget - was limited. Instead of the students making informed decisions about their options, the project manager generally had to keep track of the budget and wound up making many field decisions that could have been worked through in the design studio, given more time.

\section{WHAT CLIENT?}

Students ranged from an initial studio of third-year undergraduates in the BS Architecture program to a continuing team of volunteers from all years, including the contributions of students from the Construction Management program. The design studio, taught by a local architect, spent the first half of the semester on neighborhood background and speculative uses for the building with a social focus: a bike cooperative, refugee housing, a farmstand and teaching kitchen, and others. This preliminary exploration let the students work with the form of the house itself and also with the divergent needs of layered programmatic ideas. After Spring Break, the instructor consolidated the schemes into one hybrid, and worked with the students to detail and draft construction documents for permitting.

Throughout the process, the relationship between instructor, students, and the project manager was a microcosm of the tensions that arise in an academic design/build context. Architecture students, like most professional architects, are unused to designing without a specific client - the client for this home was the eventual buyer, unknown as the process began, and so the students had to make design decisions similarly to how a private sector developer might: with the market ultimately in mind. At the same time, the neighborhood CDC, technically the homeowner, was spearheading an initiative to provide housing for artists in the neighborhood, preferencing the students' ideas about an end user towards a young creative professional. Ultimately, the project manager acted as a "client", controlling the budget and holding veto power on any idea she deemed not sufficiently buyer-friendly; meanwhile, the students were generally designing to their own twenty-one-year-old tastes and interests. This resulted in rich and difficult conversations about livability, privacy, and other abstract questions generally not addressed in design studios. 


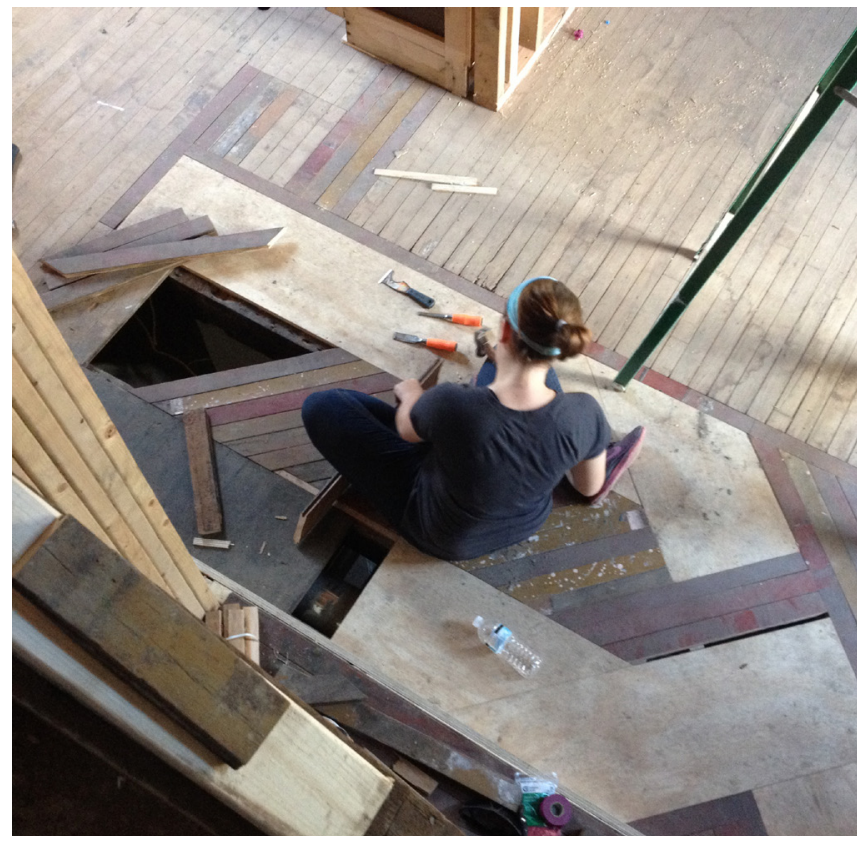

Figure 4: One of the many custom touches designed by students was the random patchwork floor repair, acknowledging the history of the building and imbuing it with new meaning

The final proposal, a one-bedroom loft house with flex space for creative work, moved forward into construction despite the advice of a real estate professional who advised at least two bedrooms in order to more easily secure a mortgage. This tension between Cleveland's highly conservative bank lending climate and the creative, out-of-the-box ideas generated by the architecture students complicated the construction and sale of the house; however, the program's original mission of harnessing alternative visions for Cleveland's vacant houses was perhaps bound to necessitate a one-of-a-kind approach. The idea was to inspire, not imitate, existing development.

\section{WHO DECIDES?}

Throughout the project, the stakes, as they always are for design/build, were high: "testing to failure" is not an option when the experiment needs to be habitable and marketfriendly. And yet, clearly standard solutions for rehabbing Cleveland's vacant housing were not viable in neighborhoods like St Clair-Superior. The true task of the leadership was to balance creative, budget-friendly design ideas with the needs of an uncertain end user.

The students were creative engines and raw muscle power; however, they were not the ultimate decision-makers on the project. As with all design/build, students are accustomed to having an individual design project where they make each and every decision, and they can chafe at this newly constricted team context with real-world consequences to their experimental ideas. Instead, the leadership team tried to impart the opportunity for learning through the group's careful consideration and occasional dismissal of their individual ideas for various budgetary and pragmatic reasons. Though at first disappointed to have their designs changed, absorbed, or rejected, the students quickly grasped the importance of the larger collaborative vision and eagerly contributed to the vetting process.

A fundamental argument of any design/build program is that students learn different but equally important lessons when brought along in a real-life construction scenario as they do in a theoretical design studio. Neither should exist in an overall architectural education independently of the other. In actuality, many of the Cleveland rebuild students expressed their newfound appreciation for the lessons of their materials and methods courses when faced with the physical reality of their two-dimensional linework. When students are accustomed to working solely with lines and planes, questions of form often dominate their decision making; however, when handling 90-year-old bricks and plaster, material, texture, and formerly abstract considerations like light quality take on newly profound importance. These lessons are then brought back into subsequent design studios for further exploration.

In the Cleveland house rebuild, erring on the side of the student experience was simply not an option. Far more important to the overall project was the success of the house as a future home, meaning its marketability and durability were the priority above and beyond individual student wishes. The studio instructor and the project manager, though always collaborative, were sometimes in conflict about the best course of action. In the end, the option which created the quickest path forward and the lowest strain on the budget generally won out. Occasionally, however, some bespoke touches - like a custom welded handrail, a reclaimed hardwood countertop from Cleveland street trees, and a patchwork floor repair - were executed despite their additional time, with the general consensus that it would be exactly these beautiful one-of-a-kind details that would best market the house to a prospective buyer.

\section{WHAT IS SUCCESS?}

To date, the single design/build house in St. Clair-Superior remains the only house renovated by the University's architecture program. Given the logistical and financial challenges of the project, the University is hesitant to replicate the process. A second house, a rowhome in the neighborhood needing less intensive renovation, was identified by the CDC and an Interior Design studio at the University has generated budget-friendly ideas for updating it; however, any actual construction seems unlikely in the near future. In this way, one of the project's original goals - to forge a replicable, financially feasible path for rehabbing Cleveland's vacant houses - has not come to pass.

Viewed through different outputs, however, the project remains a success. Several of the architecture students in 
the course were so inspired by the opportunity of Cleveland's vacant housing stock that, upon graduation, they either joined small-scale experimental practices or began working with contractors on hands-on house renovation. Many more students, no matter their eventual career trajectory, voiced their new awareness of economic disparity and their commitment to work with communities in their practice, driven largely by their personal interactions with neighbors living on the block throughout the course of the demolition and reconstruction. This personal experience in listening to and responding to underserved populations will serve all students involved throughout their careers.

Moreover, the Design Center has since synthesized many of the design ideas examined in the design/build project in a publication released in Summer 2017, which was distributed widely to neighborhood CDCs and housing organizations ${ }^{4}$. The publication encourages small-scale developers and homeowners to update their houses to make them more contemporary, livable, and energy-efficient. Funded by a historic preservation organization, the guide argues that the true aim of historic preservation in a city like Cleveland should be to stabilize neighborhoods, not simply to perfectly restore singular buildings; these old homes are assets to our historic neighborhoods, and can be reclaimed as vibrant pieces of our urban fabric. It is the hope of the Design Center that through this publication these low-cost high-impact design ideas first explored by students can reach a mass audience and have positive impact on Cleveland's many vacant houses.
Finally, though one single house seems a small success with thousands in need, it has been transformed into a modern residence for the buyer who has since taken the loft space and custom-tailored it to his own needs. The formerly vacant lot next door, landscaped and donated by the Land Bank, is now functionally his back yard space. Residents up and down the block, formerly faced with yet another vacant and condemned property, instead have a new neighbor invested in their local community.

\section{CONCLUSIONS:}

This project attempted to answer the question: can a lowcost residential design/build program point a way forward when tackling the city's vacant housing? Can we leverage design students' inherent creativity and problem-solving to bridge a development gap?

The answers to these open questions turned out to be complex, with mixed results. A single home has been reclaimed and saved from demolition, but the lessons learned along the way point to the difficulty in bringing those ideas to scale, both within academia and in the larger development community. Any future design/build project in one of Cleveland's vacant houses would have to be less architecturally radical and take less time exploring in the design studio, in order to produce a consolidated design proposal, construction documents, permitting, and construction in an incredibly compressed timeline. Alternatively, increased collaboration between design disciplines - architecture, interior design, and
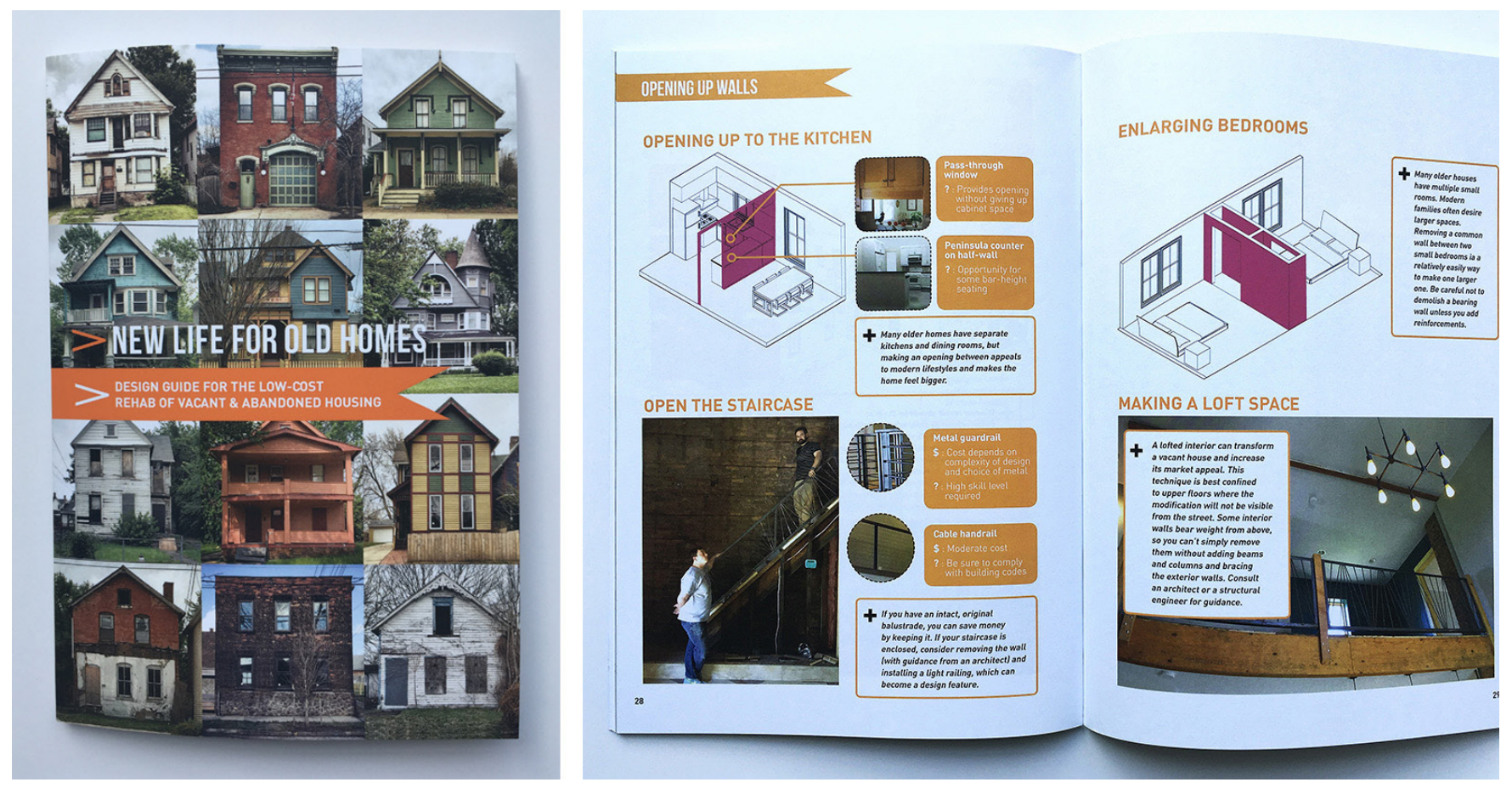

Figure 1: A 2017 publication by the University's Design Center summarizes lessons from the design/build process in the hopes of inspiring homeowners and small-scale developers and bringing the low-cost high-impact design ideas to scale ${ }^{4}$ 
construction management - could lead to a project where each program's students tackle one specific aspect of the overall whole across multiple semesters. Either of these possibilities as of now seem unlikely, leaving countless other houses untouched.

From a practical perspective, takeaways for other adaptive reuse design/build programs, and for the Cleveland program specifically, include: appoint a final definitive decision-maker, either the instructor or the project manager; locate a house in a neighborhood with at least minimum market demand, in order to sell the house for enough money to replicate the process; work more closely with construction management students and faculty to grasp the real costs of each specific design idea and more confidently vet them for budget; and locate a house with enough salvageable components remaining to limit the time and expense of a full-gut demolition.

Pedagogically, bringing the students along on the exploration of these broader ethical questions - what house, what market, what client, who decides - proved the most fertile territory for discussion, debate, and alternate perspectives. These questions were open, and should perhaps remain so for any future project; working through the nuances of rebuilding in a complex real-life neighborhood should not be solved wholly upfront, without the engagement of the students, when the alternative is to use the exploration as an opportunity to dig into the rich substance of who their work truly is, and should be, for.

Ultimately, the design/rebuild studio was an opportunity for architecture students to get out of the studio and see, feel, and experience their design decisions first-hand. Additionally, the opportunity to collaborate with construction management students on the project brought a new appreciation for related building disciplines, an attempt to break out of educational silos that will serve the students well throughout their career. Perhaps most importantly, though, the students came away from the rebuild process inspired by the community members living in our urban neighborhoods; and by the enormous design and rebuilding opportunity of Cleveland's vacant houses.

\section{ENDNOTES}

1 Northeast Ohio Sustainable Communities Consortium, 2013.

22015 Cleveland Property Inventory, Western Reserve Land Conservancy Thriving Communities Institute.

32015 Cleveland Property Inventory, Western Reserve Land Conservancy Thriving Communities Institute; and the Cleveland Urban Design Collaborative.

4 New Life for Old Homes: Design Guide for the Low-Cost Rehab of Vacant \& Abandoned Buildings. Cleveland Urban Design Collaborative, 2017. https:// issuu.com/ksuCUDC/docs/ohf_issuu. 